\title{
DA SECRETARIA DE SAÚDE AO CONSELHO: ANÁLISE DE RELATÓRIOS DE PRESTAÇÃO DE CONTAS COM BASE NAS CARACTERÍSTICAS QUALITATIVAS DA INFORMAÇÃO CONTÁBIL
}

\section{FROM THE HEALTH SECRETARY TO THE COUNCIL: ANALYSIS OF THE ACCOUNTANCY REPORTS BASED ON THE QUALITATIVE CHARACTERISTICS OF ACCOUNTING INFORMATION}

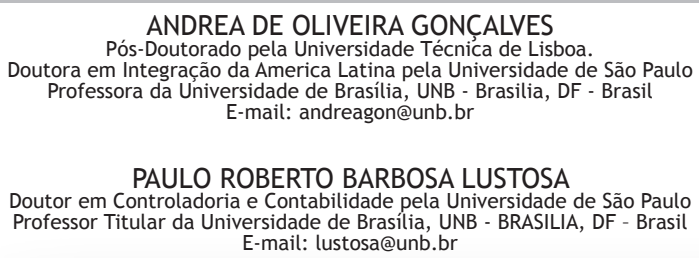

\section{RESUMO}

RODRIGO SOUZA GONCALVES

Doutorando pelo Programa Multiinstitucional em Ciências Contábeis UnB/UFRN/UFPB

Professor da Universidade de Brasília, UNB - Brasilia, DF - Brasil E-mail: rgoncalves@unb.br

EMANOEL CARLOS CELESTINO

Graduado em Ciências Contábeis - Universidade de Brasília - UnB E-mail: emanoelcelestino@yahoo.com.br

0 artigo tem como foco a utilidade das informações contábeis como ferramenta de auxílio ao exercício das atribuições de planejamento, gestão e controle, inerentes aos Conselhos de Saúde. Neste sentido, o artigo analisa os resultados de estudo exploratório, de natureza qualitativa (GIL,1999), sobre as informações contidas nos relatórios de prestação de contas da Secretaria de Saúde do Distrito Federal ao Conselho de Saúde do Distrito Federal. Buscouse a partir de Hendriksen e Van Breda (1999), Glautier e Underdown (1994) e Riahi-Belkaoui (2004) as características qualitativas necessárias à informação a ser destinada ao usuário. A partir de tais características, construiu-se um instrumento para avaliar os relatórios de prestação de contas. A coleta dos dados foi realizada em relatórios de prestação de contas apresentados pela Secretaria ao Conselho nos últimos trimestres dos exercícios financeiros de 2003 a 2006. Os resultados indicam a necessidade de melhorias no conteúdo das informações dos relatórios, bem como nos objetivos e metas estabelecidos para o exercício seguinte, para que o relatório tenha utilidade informacional para contribuir com as atribuições legais inerentes aos Conselhos de Saúde.

Palavras-chave: Informações Contábeis; Conselhos de Saúde; Accountability.

\section{ABSTRACT}

The focus of this article is the effectiveness of accounting information as a supportive tool to the execution of the attributions of planning, management and control inherent to the Health Councils. Thus, the article analyses the results of qualitative nature exploratory study (GIL,1999), with regards to the information reported on the accountancy reports of the Health Secretary of the Federal District to the Health Council of the Federal District. The qualitative characteristics necessary to the information designated to the users were based upon Hendriksen and Van Breda(1999), Glautier and Underdown (1994) and RiahiBelkaoui (2004). Such characteristics allowed the designing of an instrument to evaluate the accounting reports. The data collection was accomplished through the accounting reports presented by the Secretary to the Council on the last quarters of the 2003 and 2006 financial years. The results have shown the necessity of improvement on the contents of the information reports, as well as on the goals and aims established for the following financial period so that the report can have informational usefulness regarding the contribution to the legal attributions inherent to the Health Councils.

Key words: accounting information, health councils and accountability 


\section{INTRODUÇÃO}

No Brasil, existem 5.561 conselhos de saúde e para que possam exercer de forma otimizada suas atribuições junto ao Sistema Único de Saúde - SUS há a necessidade de que esses conselhos obtenham informações acerca da gestão empreendida pelo gestor do SUS. Nesse sentido, a legislação estabelece a obrigatoriedade de o gestor do SUS fornecer informações acerca da gestão, em cada esfera governamental, ao Conselho de Saúde por meio de prestação de contas (LEI FEDERAL 8689/93; art. 12).

Essa prestação de contas, também conhecida pelo termo accountability (MOSHER, 1968) permite o exercício do controle social a ponto de avaliar as ações do gestor identificando, por exemplo, se os recursos destinados à área de saúde estão sendo efetivamente alocados em seus destinos finalísticos (PIOLA; REIS; RIBEIRO, 2001).

Desta forma, a prestação de contas, entendida aqui como informações prestadas ao Conselho de Saúde acerca da gestão do Sistema, na esfera governamental correspondente, pode ser vista de dois ângulos diferentes. De um lado, como valor preditivo, ou seja, subsidiando decisões acerca de eventos futuros, tais como o montante e a forma de alocação dos recursos disponíveis. De outro, como valor confirmativo, ou seja, auxiliando na avaliação de eventos ocorridos tais como o montante e a forma de recursos aplicados em determinado programa de saúde e resultados respectivos.

Sob este prisma, a prestação de contas da Secretaria ao Conselho deve também subsidiar o cumprimento de suas atribuições legais no que se refere aos processos de planejamento - valor preditivo - e controle - valor confirmativo - das políticas de saúde. Portanto, nesta perspectiva, este trabalho analisa se as informações divulgadas ao Conselho Distrital de Saúde (CSDF) pela Secretaria de Saúde do Distrito Federal (SES/DF) apresentam as características qualitativas necessárias para que este Conselho cumpra com suas atribuições legais de auxílio ao gestor na formulação de estratégias e controle da execução das políticas públicas de saúde.

0 artigo está estruturado em cinco seções. Esta primeira seção contextualiza e apresenta as questões norteadoras bem como objetivos propostos. $\mathrm{Na}$ segunda seção - referencial teórico - discute-se sobre os conselhos e o papel de controle que exercem, bem como a obrigatoriedade do gestor do SUS de prestar contas e o financiamento da saúde. Na terceira seção apresenta-se o percurso metodológico da pesquisa, bem como as características qualitativas da informação contábil. E, por fim, na quarta e quinta seções apresentam-se a análise, discussão dos resultados e as conclusões obtidas. 


\section{REFERENCIAL TEÓRICO}

\subsection{ACCOUNTABILITY E CONTROLE SOCIAL}

A ideia de participação e controle social em saúde corresponde a uma variedade de enfoques, delineados a partir de distintos contextos sócio-econômico-culturais. O controle social em saúde surge a partir dos textos constitucionais de 1988, no momento em que há o resgate da importância da participação popular nas decisões de Governo. Este, portanto, é entendido como o controle que os cidadãos exercem de forma direta sobre as ações do Estado, ou seja, o controle da sociedade sobre o Estado.

Ao tratar de controle social, torna-se imprescindível discorrer sobre accountability, dado que os conceitos se completam principalmente quando ambos referem-se a transparência. Efetivamente, o termo accountability na sua acepção original e de difícil tradução (CAMPOS, 1990), diz respeito al cumplimiento de una obligación del funcionario público de rendir cuentas, sea a un organismo de control, al parlamento o a la sociedad misma (CLAD, 2000, p. 329). Desta forma, esta obrigatoriedade é pertinente à palavra e deve ser percebida pelo detentor de cargo público.

Os conceitos que envolvem a accountability, como o de prestação de contas, presentes em algumas sociedades, apresentam um leque de instrumentos criados e aprimorados ao longo dos anos, que permitem o controle dos agentes públicos e sua consequente responsabilização (O’DONNELL, 1998; DAHL,1997). Especialmente no caso do Brasil, na área de saúde apresenta-se o Conselho de Saúde que tem como uma de suas atribuições o controle, tema da próxima seção.

\subsection{CONSELHOS DE SAÚDE E A ATRIBUIÇÃO DE CONTROLE}

Os conselhos de saúde são instâncias que visam promover a participação da sociedade na definição e execução das políticas públicas de saúde. A participação da comunidade e os conselhos de saúde encontram respaldo institucional a partir da Constituição Federal de 1988 e da Lei Federal 8142/90. Todavia, o nascimento do Conselho como instrumento de participação da sociedade civil antecede a estes documentos legais.

Contudo, esse fenômeno de legalização da participação civil não nasce apenas da vontade do legislador. Segundo Silva (2005) esses movimentos sociais e populares começam a ter destaque nos anos 80 - efetivamente reconhecidos na CF de 1988, pois reivindicavam na época, saúde de boa qualidade e pública, em decorrência da falência do modelo de assistência que não atendia mais.

No que diz respeito às atribuições dos conselhos, a lei estabelece que são órgãos deliberativos aos quais compete atuar na formulação de estratégias e no 
controle da execução das políticas públicas de saúde conforme art. $1^{\circ}$, § $2^{\circ}$ da Lei Federal $n^{\circ}$. 8.142/1990.

No âmbito do Distrito Federal o Conselho de Saúde, embora tenha sido criado em 1973, antes do advento das normas constitucionais de 1988, não tinha, no início, o objetivo de ser instrumento de participação da comunidade. Era um órgão consultivo, ligado ao governo e desprovido de participação da sociedade na sua composição. Somente em 1989 o Conselho passou por alterações que redefiniram a sua competência e composição passando, assim, a abarcar, de forma paritária a participação da comunidade.

Atualmente o CSDF é regido pela Lei Distrital $n^{\circ} .469 / 1993$ a qual assim o define: “Art. $1^{\circ}$ - O Conselho de Saúde do Distrito Federal (CSDF) é órgão permanente de deliberação coletiva, integrante da estrutura administrativa da Secretaria de Saúde". 0 artigo $3^{\circ}$ da mesma lei enumera as competências do Conselho como definir e controlar diretrizes gerais da saúde; estabelecer estratégias e mecanismos de coordenação do SUS; fiscalizar a adequação do fluxo de desembolso de recursos repassados à Secretaria de Saúde e ou/ fundo de Saúde bem como propor critérios para a programação e execução financeiras/orçamentárias.

Juntamente com a criação dos conselhos de saúde e no intuito de dotá-los de mecanismos hábeis para o exercício de suas atribuições, a legislação estabeleceu também que o gestor do SUS, em cada esfera de governo, preste contas da gestão aos conselheiros, ponto a ser analisado no tópico subsequente.

\subsection{A PRESTAÇÃO DE CONTAS DO GESTOR DO SUS AO CONSELHO DE SAÚDE}

Para que os conselhos possam atuar no planejamento e controle dos atos governamentais, é essencial que a administração pública preste contas de seus atos. A prestação de contas, nesse contexto, deve evidenciar a atuação do governo e seus resultados para que os mesmos possam ser avaliados e controlados. Por outro lado, faz-se necessário que o governo evidencie seus planos e propostas para que os representantes da comunidade possam discutir e deliberar a respeito.

Nesse sentido a Lei Federal $n^{\circ} .8689 / 1993$ determina que o gestor do Sistema Único de Saúde em cada esfera de governo preste contas ao Conselho de Saúde trimestralmente. A referida lei, juntamente com a Resolução n ${ }^{\circ}$. 333/2003 do Conselho Nacional de Saúde, dispõe sobre o conteúdo da prestação de contas, no qual inclui: andamento da agenda de saúde pactuada; relatório de gestão; montante, fonte e forma de aplicação dos recursos aplicados; auditorias iniciadas e concluídas no período; oferta e produção de serviços na rede assistencial.

Embora a legislação estabeleça a obrigatoriedade da prestação de contas do governo perante os conselhos, há obstáculos a serem superados para que este instrumento se torne uma ferramenta útil aos conselheiros. Bicalho (2003), por exemplo, aponta que têm sido utilizados instrumentos complexos na prestação de 
contas que dificultam a compreensão, a avaliação e consequentemente o controle social.

Essa dificuldade decorre dentre outros motivos, em virtude da prestação de contas envolver aspectos financeiros, orçamentários e outros ligados aos recursos necessários ao funcionamento do SUS, e pela ausência de instrumentos que permitam sua avaliação. Diante disso, surge a necessidade de se buscar alternativas que auxiliem os conselheiros de saúde a avaliarem a prestação de contas que é realizada por meio dos relatórios elaborados pelas Secretarias de Saúde, de modo a permitir que aquele possa identificar se as informações necessárias foram prestadas e ainda, se estas são úteis no processo de controle social.

Nesse sentido, a contabilidade pode contribuir na medida em que preconiza em sua teoria características que devem conter a informação para que a mesma seja útil ao usuário. Assim sendo, a seção seguinte busca descrever estas características e relacioná-las com os relatórios de prestação de contas e com as necessidades dos conselhos de saúde.

\section{PERCURSO METODOLÓGICO}

Com a proposta de analisar as características qualitativas das informações contidas nos relatórios de prestação de contas o presente estudo classifica-se como pesquisa qualitativa do tipo exploratório-descritiva (GIL, 1999).

O objeto de análise da pesquisa delimita-se na avaliação da informação contábil sob o ponto de vista de suas características qualitativas conforme apresentada na próxima seção.

\subsection{INFORMAÇÃO CONTÁBIL: CARACTERÍSTICAS QUALITATIVAS}

A necessidade de descrever as características qualitativas da informação contábil está relacionada à necessidade de apresentar informações úteis ao usuário e, ao mesmo tempo, evitar a apresentação de informações desnecessárias.

No âmbito da prestação de contas aos conselhos de saúde isso é importante na medida em que as informações precisam ser apresentadas aos conselheiros de forma que os auxiliem no exercício de suas atribuições legais. Além disso, a decisão de apresentar informações financeiras deve considerar a relação entre o seu custo e benefício, abstendo-se de apresentar informações cujos custos superem os respectivos benefícios. Embora esta mensuração seja difícil, a análise das características da informação pode ajudar na decisão de divulgar ou não determinada informação.

Autores como Hendriksen e Van Breda (1999), Glautier e Underdown (1994) e Riahi-Belkaoui (2004) afirmam que os principais aspectos necessários à informação para que a mesma seja útil são a materialidade, a relevância e a confiabilidade. 
Para ludícibus, Martins e Gelbcke (2003, p. 68) a materialidade está relacionada à divulgação de “eventos que refletem tendências do empreendimento".

Glautier e Underdown (1994), por sua vez, entendem que a materialidade é o requisito mínimo que deve conter a informação para que a mesma seja útil.

Para Hendriksen e Van Breda (1999), a informação pode ser considerada material se o conhecimento da mesma for importante para o usuário nas suas decisões. $E$, ainda segundo os mesmos autores, quando da decisão de divulgar ou não determinada informação, a materialidade pode ser analisada com base nos seguintes itens: dados quantitativos; grau de itemização de dados quantitativos; relações especiais entre a entidade e indivíduos ou grupos específicos; planos e expectativas da administração.

No que diz respeito aos relatórios de prestação de contas essa característica da informação é importante à medida que permite a reflexão acerca de quais informações são realmente importantes para os conselheiros, o que possibilita que os mesmos exijam que gestor inclua tais informações nos relatórios de prestação de contas.

Outra característica apresentada como necessária para tornar a informação útil tem-se a relevância, que, para Riahi-Belkaoui (2004) pode ser vista como o link entre a informação contábil e a necessidade de uma eficiente alocação de recursos. Já para Hendriksen e Van Breda (1999, p. 97) a relevância é alcançada à medida que a informação auxilie "os usuários a fazer predições sobre o resultado de eventos passados, presentes e futuros, ou ainda confirmar ou corrigir expectativas anteriores". Para os mesmos autores, a relevância é função de três aspectos: valor preditivo; valor confirmativo e oportunidade.

Para os conselhos de saúde estes aspectos são de fundamental importância. 0 exercício das atribuições dos conselhos, tais como, o controle e o acompanhamento dos atos da gestão, a discussão e deliberação das estratégias a serem adotadas, bem como a avaliação das decisões tomadas torna-se mais difícil ou até mesmo impossível se os conselheiros não estiverem de posse de informações relevantes relacionadas aos atos e acontecimentos ligados à gestão.

Nesse sentido, os relatórios de prestação de contas precisam como condição mínima, possibilitar, de um lado, o acompanhamento da destinação e alocação de recursos financeiros e, de outro, a predição acerca da disponibilidade futura de recursos financeiros e das necessidades efetivas desses recursos na área da saúde.

Além da materialidade e da relevância, outra característica apontada como necessária para tornar a informação útil é a confiabilidade. Para Hendriksen e Van Breda (1999) a confiabilidade da informação diz respeito à ausência de erros e/ou vieses, representando fielmente os eventos que visa representar.

Se as informações constantes dos relatórios de prestação de contas não forem confiáveis não poderão ser utilizadas como instrumento de planejamento e controle pelos conselheiros. 
A confiabilidade das informações prestadas aos conselhos pressupõe que a escolha quanto à divulgação não seja feita segundo a conveniência dos gestores e, também, que estes não omitam informações, pois uma possível omissão pode abrir espaço para que os relatórios sejam contaminados com viés pessoal (GLAUTIER; UNDERDOWN, 1994).

Para Glautier e Underdown (1994) a informação confiável possui as seguintes características:

1. Conteúdo - a informação relevante deverá apresentar de maneira fidedigna as transações e eventos que ela visa representar, sendo necessário ainda que ela apresente congruência com a realidade econômica e não meramente com a forma legal;

2. Valor descritivo e mensurável - a informação deverá ser capaz de ser mensurável e permitir a possibilidade de estabelecer projeções sobre eventos futuros;

3. Neutralidade - esta característica está relacionada ao fato de que a informação não deve ser escolhida ou selecionada pelos gestores (JONAS; BLANCHET, 2000);

4. Precisão - tal característica está relacionada à necessidade de não omissão de informações, pois, isto pode causar uma falsa informação ou pode direcionar para um entendimento não confiável ou deficiente;

5. Prudência - relaciona-se ao estabelecimento de estimativas quanto à ocorrência de eventos futuros que no momento de sua elaboração são incertos de ocorrerem.

\subsection{COLETA DOS DADOS}

Os dados foram coletados nos relatórios de prestação de contas apresentados trimestralmente pela SES/DF ao CSDF nos exercícios financeiros de 2003 a 2006. Escolheram-se os referidos relatórios por serem considerados como o instrumento legal de prestação de contas entre os entes envolvidos. Quanto ao trimestre, fora escolhido o último dentre os quatro trimestres de cada exercício financeiro em virtude das características intrínsecas do instrumento, como a avaliação de informações do exercício seguinte.

Além dos relatórios de prestação de contas, outros documentos subsidiaram a coleta de dados. São elas: PPA (2004-2007) e os pareceres emitidos pelo CSDF dos respectivos relatórios de prestação de contas.

Os dados de interesse da pesquisa foram coletados a partir das características das informações propostas por Glautier e Underdown (1994), Hendriksen e Van Breda (1999) e Riahi-Belkaoui (2004). 
A primeira dimensão tratada na pesquisa relaciona-se à “materialidade", que se refere ao fato de a informação refletir tendências do empreendimento e de ser importante para as decisões do usuário (IUDÍCIBUS; MARTINS; GELBCKE, 2003; HENDRIKSEN; Van BREDA, 1999). Nesta dimensão encontram-se os indicadores: dados quantitativos, grau de itemizacao dos dados; relações entre SES/DF e o Conselho de Saúde; planos e expectativas relevantes da administração.

Na segunda dimensão trata-se da "relevância" que diz respeito à divulgação de informações que auxiliem o usuário a avaliar a alocação dos recursos e ainda predizer decisões futuras. É constituída pelos indicadores valor preditivo; valor confirmativo; oportunidade.

Por fim, a terceira dimensão é a "confiabilidade", que para Hendriksen e Van Breda (1999) está relacionada à ausência de erros e/ou vieses. Complementando, Glautier e Underdown (1994) definem que a informação confiável possui como características, os indicadores: conteúdo, neutralidade, precisão e prudência. Desse modo, considerando as características de cada indicador apontado será atribuída no mínimo uma variável correspondente, que será apresentada individualmente na seção - análise dos resultados.

\subsection{OPERACIONALIZAÇÃO DA ANÁLISE DOS DADOS}

Para possibilitar a análise dos dados, utilizaram-se os princípios da análise documental e foram estabelecidas quatro categorias teóricas que possuem uma amplitude desde restrita à ampla. Abaixo serão apresentadas como serão classificadas as informações em cada categoria.

(1) Restrita - a informação requerida não é divulgada;

(2) Baixa - a informação requerida não é divulgada, contudo, o gestor manifestou intenção em passar a divulgar;

(3) Média - o gestor divulga a informação requerida, mas não o faz de forma completa segundo os critérios estabelecidos no instrumento de evidenciação;

(4) Ampla - o gestor divulga a informação requerida de forma completa segundo os critérios estabelecidos no instrumento de evidenciação.

\subsection{LIMITAÇÕES METODOLÓGICAS DO TRABALHO}

Quanto às limitações intrínsecas ao trabalho tem-se o fato de que as considerações estão restritas ao CSDF. Pode-se colocar também o fato de que não foi elaborado um instrumento para avaliar os pareceres do CSDF e, também não se procurou avaliar as dificuldades encontradas pelos conselheiros quando da leitura dos relatórios de prestação de contas.

Quanto à utilização das características qualitativas da informação contábil, cumpre salientar que o seu uso tem por objetivo compor o instrumento de coleta de 
dados quanto o apontamento das variáveis ora selecionadas, não havendo, portanto, a pretensão deste em mensurar ou avaliar suas dimensões (materialidade, relevância e confiabilidade).

Além disso, cabe ressaltar que o conteúdo dos relatórios de prestação de contas vai além dos aspectos avaliados neste trabalho, ou seja, há informações nestes relatórios que não foram avaliadas por não se enquadrarem nos critérios estabelecidos no instrumento construído para sua avaliação.

\section{ANÁLISE E DISCUSSÃO DOS RESULTADOS}

A partir dos estudos Glautier e Underdown (1994), Hendriksen e Van Breda (1999) e Riahi-Belkaoui (2004) foram estabelecidas três dimensões - Materialidade, Relevância e Confiabilidade - para o instrumento de avaliação dos relatórios. A partir das características componentes de cada uma destas dimensões, apontadas por esses autores, foram estabelecidos indicadores, os quais, por sua vez, foram os elementos básicos para que se estabelecessem quais variáveis seriam coletadas para avaliação dos relatórios.

Os elementos que permitem avaliar a materialidade da informação são: os dados quantitativos, grau de itemização dos dados quantitativos, relações entre a administração da entidade e a comunidade e os planos e expectativas relevantes da administração (HENDRIKSEN; Van BREDA, 1999).

A variável analisada no indicador dados quantitativos foi a evidenciação da aplicação dos recursos financeiros, que objetiva avaliar a evidenciação dos recursos aplicados na área da saúde de forma a demonstrar o quanto se gastou em cada ação de governo (projetos, atividades e operações especiais) e por programas de governo no trimestre em análise. Os resultados apontam que nos períodos de 2003 e 2004 foi evidenciado o montante dos recursos aplicados discriminando-os por ações e por programas de governo, apresentando-se o quantitativo aplicado no trimestre em análise conforme tabela 7 (sete) e anexo II do relatório de 2003 e tabela 6 (seis) e anexo I do relatório de 2004. Assim, a evidenciação do conteúdo avaliado por esta variável tende a ser AMPLA para os exercícios de 2003 e 2004.

Nos exercícios seguintes - 2005 e 2006 - contudo, embora tenha sido evidenciado o quantitativo de recursos aplicados, não se evidenciou o montante relacionado ao trimestre em análise. Constatou-se, ainda, que o relatório referente ao exercício de 2006 não discriminou os recursos aplicados por programas de governo. Dessa forma, a evidenciação do conteúdo avaliado por esta variável, considerando a não evidenciação relativamente ao trimestre em análise, tende a ser MÉDIA nos exercícios de 2005 e 2006.

A evidenciação incompleta da aplicação dos recursos financeiros, conforme aponta os resultados obtidos para os dois últimos períodos avaliados, implica dificuldades no exercício da atribuição legal de controle que é conferida ao Conselho. 
Isso porque informações acerca da aplicação dos recursos são necessárias para se avaliar situações tais como a realização da previsão de recursos materializada no PPA e no orçamento aprovado no exercício anterior, o atendimento às prioridades quanto à destinação de recursos estabelecida em outros momentos, o confronto dos resultados obtidos com os recursos gastos para alcançá-los e a verificação do efetivo cumprimento das normas relacionadas ao financiamento da saúde.

No que diz respeito ao indicador grau de itemização dos dados quantitativos, a variável estabelecida foi a especificação da fonte dos recursos financeiros cujo objetivo é avaliar se as informações apresentadas permitem aos usuários saber como estão sendo financiadas as atividades do SUS, quais entidades, governamentais ou não, estão contribuindo e qual é o percentual de contribuição de cada uma. A evidenciação das fontes dos recursos aplicados na área da saúde é importante na medida em que permite ao Conselho perceber os principais financiadores do setor e também para que possa fiscalizar as normas constitucionais que estabelecem critérios para a destinação de recursos para a área da saúde.

Constatou-se que os recursos financeiros disponíveis para financiamento das ações e serviços de saúde foram apresentados de forma a demonstrar as fontes dos recursos e também o quanto foi disponibilizado no trimestre em análise em todos os exercícios analisados. No relatório referente ao exercício de 2003 os dados foram apresentados na tabela 2 (dois) do item 3.1 "Da Receita"; no relatório referente ao exercício de 2004 os dados foram apresentados na tabela 1 (um) do item 3.1 "Da Receita"; no relatório referente ao exercício de 2005 os dados foram apresentados no item 5 (cinco) “Análise da Receita pelo FSDF (...)". Já no relatório referente ao exercício de 2006 os dados foram apresentados no item 6 (seis) "Análise da Receita Realizada (...)". Assim, a evidenciação do conteúdo avaliado por esta variável tende a ser AMPLA em todos os exercícios analisados.

No que trata sobre relações entre a SES/DF e o Conselho a variável estabelecida para este elemento foi a participação do Conselho nas decisões da Secretaria de Saúde, que avalia a evidenciação do posicionamento da SES/DF frente às deliberações/recomendações do Conselho de Saúde nos pareceres emitidos quando do exame os relatórios de prestação de contas. Não foi constatada, nos relatórios analisados, nenhuma menção a atitudes e/ou posicionamento tomados pela SES/ DF frente a qualquer manifestação do Conselho nos pareceres dos relatórios de prestação de contas. Contudo, observou-se a existência de recomendações/sugestões nos pareceres aos relatórios dos trimestres $3^{\circ} / 2003,3^{\circ} / 2004$ e $3^{\circ} / 2005$. O parecer referente ao $3^{\circ}$ trimestre/2005, por exemplo, traz: “1 $1^{\circ}$ - Que no relatório do próximo e último trimestre venha descritos os repasses de recursos da Fonte 101, 102 e 106". 0 parecer referente ao $3^{\circ} / 2006$, até o fechamento deste trabalho, ainda não havia sido elaborado pelo Conselho. Dessa forma, foram examinados os pareceres referentes aos trimestres $1^{\circ} / 2006$ e $2^{\circ} / 2006$ e constatou-se que em ambos há recomendações do Conselho para a SES/DF. Dessa forma, considerando a ausência de manifestação da SES/DF, nos relatórios de prestação de contas, frente às recomendações do Conselho, tem-se que a evidenciação desta variável, nos períodos avaliados, tende a ser RESTRITA.

O retorno da SES/DF quanto à utilização e/ou análise das recomendações feitas 
pelo Conselho se faz necessário não somente como ferramenta de gestão no processo entre os entes, mas inclusive como parte da construção do processo democrático. Fato este que reforça a representatividade dos conselhos como uma conquista no processo de democratização do Estado brasileiro. Este processo configura como um espaço público, onde a comunidade se expressa reivindicando seus direitos e controlando o Estado para que execute as deliberações oriundas desta instância.

A não divulgação do posicionamento da SES/DF frente às sugestões/ recomendações do CSDF é prejudicial à construção do processo democrático no sentido em que deixa de estabelecer um diálogo entre a administração e a comunidade reduzindo assim, o potencial do controle exercido por esta comunidade sobre os atos de gestão praticados pelo Estado. Além disso, o parecer do Conselho acerca dos relatórios de prestação de contas pode ser visto como uma ferramenta de auxílio à gestão na medida em que o Conselho pode apresentar sugestões relacionadas a dificuldades encontradas pelo gestor na administração do SUS.

Quanto o indicador, planos e expectativas relevantes da administração a variável escolhida para análise foi a evidenciação dos objetivos e metas para o exercício subsequente cujo objetivo é avaliar a evidenciação do planejamento operacional da SES/DF para o exercício seguinte incluindo os objetivos e metas que a mesma quer alcançar em cada área da saúde.

Na lei $n^{\circ}$. 3.157/2003, que dispõe sobre o PPA do Distrito Federal (2004-2007), são estabelecidas metas para a área da saúde. Todavia, observou-se a inexistência, nos relatórios relacionados aos exercícios de 2003, 2005 e 2006, de qualquer menção aos objetivos e metas da administração para o exercício seguinte. Dessa forma, a evidenciação do conteúdo avaliado por esta variável, nestes exercícios, tende a ser RESTRITA.

No exercício de 2004, contudo, constatou-se que o gestor aborda o assunto sem especificar quais seriam as suas metas e objetivos conforme a seguir: "No atual governo, a Secretaria de Saúde está mudando para melhor o planejamento...". Assim, embora traga ao relatório menção ao planejamento que está sendo feito, não diz quais são os objetivos e metas. Dessa forma, a evidenciação do conteúdo avaliado por esta variável, no exercício financeiro de 2004, tende a ser BAIXA.

A não divulgação dos objetivos e metas estabelecidas para o exercício seguinte é prejudicial ao exercício das atribuições do Conselho, sobretudo em sua atribuição legal de controlar a execução da política pública de saúde. Desta forma, o Conselho fica impedido de avaliar o plano de atuação da gestão, de avaliar se as ações a serem desenvolvidas estão, por exemplo, de acordo com o estabelecido no PPA e sintonizado com as necessidades da comunidade. Impede, também, que o Conselho possa exercer o controle prévio cobrando da Secretaria iniciativas que considere importantes, mas que esta não tenha colocado dentre os seus objetivos e metas, antes que os planos sejam executados.

Segundo Hendriksen e Van Breda (1999), no que diz respeito à dimensão relevância, o valor preditivo da informação está relacionado à necessidade de permitir predições de objetivos futuros. A variável escolhida para este indicador foi recursos financeiros previstos na proposta/lei orçamentária cujo objetivo é avaliar 
a evidenciação dos recursos financeiros previstos na área da saúde para o exercício seguinte, dispondo-os por ações e por programas de governo e, ainda, por fontes de recursos.

No relatório referente ao exercício de 2003 os recursos previstos na proposta orçamentária são apresentados discriminando-se por fontes, por programas e por ações de governo. A evidenciação segundo as fontes é apresentada na tabela 10 do item 5 “O Orçamento da SES/DF”. A evidenciação dos recursos previstos discriminados por programas e por ações de governo é apresentada, por sua vez, no anexo III do relatório de prestação de contas. Assim, a evidenciação do conteúdo proposto por esta variável, para o exercício de 2003, tende a ser AMPLA. Já nos exercícios de 2004, 2005 e 2006, tende a ser MÉDIA, uma vez que não fora divulgada as fontes de recursos, somente o montante total.

Para Hendriksen e Van Breda (1999) o valor confirmativo da informação está relacionado à confirmação ou correção de expectativas anteriores e pode ser importante para a tomada da decisão seguinte. Para este indicador foram estabelecidas a variável confronto dos resultados obtidos com as metas estabelecidas para a área da saúde, a qual busca avaliar a evidenciação dos resultados obtidos a partir da aplicação dos recursos disponíveis. Constatou-se nos relatórios dos exercícios de 2003 e 2004 a não evidenciação dos resultados obtidos nos trimestres analisados. Assim, para os trimestres avaliados nos exercícios de 2003 e 2004, a evidenciação do conteúdo avaliado por esta variável tende a ser RESTRITA.

Nos períodos avaliados dos exercícios de 2005 e 2006 observou-se, nos itens 11 a 14 do relatório de 2005 e 12 a 16 do relatório de 2006 a evidenciação de alguns resultados comparativamente com as metas estabelecidas. Levando-se em conta a omissão da apresentação de alguns resultados e metas e a ausência de justificativa para a não apresentação dos mesmos, tem-se que a evidenciação do conteúdo proposto por esta variável, para os exercícios de 2005 e 2006 tende a ser MÉDIA.

No indicador oportunidade foram estabelecidas as variáveis periodicidade de disponibilização dos relatórios e disponibilização do relatório em análise. A primeira variável avalia se o gestor está evidenciando o momento em que irá disponibilizar o próximo relatório de prestação de contas. Nos relatórios analisados não se encontrou nenhuma menção ao momento de disponibilização dos próximos relatórios. Dessa forma, nos períodos analisados a evidenciação do conteúdo proposto por esta variável tende a ser RESTRITA.

Quanto à variável disponibilização do relatório em análise, nos relatórios referentes 2003 e 2004 foi evidenciado apenas o mês de divulgação dos relatórios. Isso pode ser observado na primeira página de cada um dos documentos. Considerando que o gestor evidenciou apenas o mês de disponibilização do relatório, mas não informou sua periodicidade, a evidenciação para os exercícios de 2003 e 2004 tende a ser MÉDIA. Nos demais relatórios, observou-se a inexistência de informações referentes ao momento da efetiva disponibilização dos relatórios de prestação de contas ao Conselho de Saúde. Portanto, a evidenciação para os exercícios de 2005 e 2006 tende a ser RESTRITA. 
$\mathrm{Na}$ dimensão confiabilidade, Glautier e Underdown (1994) reforçam que a informação confiável é constituída pelos indicadores conteúdo, valor descritível $e$ mensurável, neutralidade, precisão e prudência.

Ao tratar do indicador conteúdo da informação, que demonstra de maneira fidedigna as transações e eventos, bem como representa e apresenta congruência com a realidade econômica, foram escolhidas as variáveis divulgação das prioridades para a destinação de recursos financeiros e evidenciação das retificações orçamentárias.

A primeira variável - divulgação das prioridades para a destinação de recursos financeiros - avalia a evidenciação das prioridades definidas pela gestão frente a possíveis contingenciamentos dos recursos orçamentários. Sabe-se que a programação estabelecida na lei de orçamento, no que diz respeito à arrecadação da receita, pode não realizar-se por completo ou se realizar de forma diversa do que estava previsto, acarretando uma insuficiência de recursos frente às necessidades do setor saúde. Por conseguinte, há o comprometimento da realização das ações previstas pela administração pública.

Embora do ponto de vista da eficiência da gestão, seja imprescindível estabelecer prioridades para a aplicação dos recursos financeiros destinados à área da saúde, a evidenciação das prioridades estabelecidas também é de importância fundamental para o Conselho, pois em sua competência legal atua na formulação de estratégias dando sugestões para aperfeiçoar o plano de ação do gestor. Pela análise dos relatórios de prestação de contas dos períodos avaliados dos exercícios de 2003 a 2006, constatou-se a inexistência de qualquer informação que permita aferir as prioridades estabelecidas para a execução orçamentária, demonstrando a tendência RESTRITA.

Avariável evidenciação das retificações orçamentárias avalia a evidenciação das retificações orçamentárias que envolvam a área da saúde. Esta variável é necessária porque a programação estabelecida na lei de orçamento pode sofrer alterações que modifiquem a destinação dos recursos para a área da saúde seja realocando de um programa para outro, seja reduzindo o quantitativo de recursos ou, até mesmo, aumentando os recursos financeiros destinados à saúde.

Nos períodos avaliados dos exercícios de 2003 a 2005, constatou-se a inexistência de informações que possibilitem aferir se existiram e quais foram as retificações orçamentárias ocorridas no período. Assim, a evidenciação do conteúdo proposto por esta variável, nos períodos avaliados dos exercícios de 2003 a 2005, tende a ser RESTRITA.

No relatório de prestação de contas do $4^{\circ}$ trimestre do exercício 2006 constatouse, todavia, que o gestor afirma existirem retificações orçamentárias. A evidenciação apresentada pelo gestor consta do item 9.1 "O Exercício Financeiro de 2006" e encontra-se reproduzida a seguir: "Este orçamento aprovado sofreu remanejamentos durante o exercício (suplementações/cancelamentos), atingindo uma dotação final de R\$ 1.365.697.669 (...)". Dessa forma, considerando que o gestor deixou clara a existência de retificações orçamentárias, mas não evidenciou quais programas foram alvos de tais remanejamentos, a evidenciação do conteúdo avaliado por esta variável, em 2006, tende a ser MÉDIA. 
Os conteúdos avaliados, por estas duas últimas variáveis, estão relacionados. A não evidenciação das prioridades para a aplicação dos recursos disponíveis impacta a confiabilidade da informação no sentido de que o plano estabelecido pela gestão necessita considerar possíveis problemas que poderão ocorrer, como por exemplo, dificuldades na arrecadação das receitas do Estado, o que pode acarretar uma quantidade de recurso financeiro menor que a prevista inicialmente. Por outro lado, a não evidenciação das retificações orçamentárias ou, pelo menos dizer se existiram ou não, impacta a confiabilidade da informação, pois coloca em dúvida a sua fidedignidade no que diz respeito à programação orçamentária.

Ao tratar do indicador valor descritível e mensurável foi estabelecida a variável previsão de recursos para os exercícios compreendidos no PPA para a área da saúde, que avalia a evidenciação de informações relacionadas à programação de recursos financeiros estabelecidas neste Plano no âmbito do Distrito Federal.

Nos relatórios de 2003 a 2006 observou-se a inexistência de qualquer menção à previsão de recursos para os exercícios compreendidos no PPA, demonstra uma tendência RESTRITA.

Destaca-se que oPPAéconhecido como instrumento de planejamento estratégico de médio prazo da administração pública (CARVALHO, 2006). Trazer as previsões de recursos estabelecidas neste instrumento de planejamento governamental para a prestação de contas é fundamental para munir os conselheiros de informações acerca do planejamento governamental, num horizonte temporal maior que aquele possibilitado pelo orçamento.

Dessa forma, a não divulgação dessas informações, como se observa, reduz a potencialidade da prestação de contas como auxílio aos conselheiros na realização de suas atribuições legais. Dado que reduz a amplitude temporal em que os mesmos exercem o seu controle, impedindo, assim, a adoção de medidas preventivas e reduzindo a capacidade de os mesmos exercerem o controle da execução das políticas de saúde empreendidas pela gestão e da destinação de recursos para a área da saúde.

O próximo indicador a ser analisado é a neutralidade, que está relacionada ao fato de a mesma não ser escolhida pelos gestores. Para Jonas e Blanchet (2000) a neutralidade pode ser identificada nas informações contábeis a partir dos comentários a respeito do desempenho alcançado face os objetivos e metas traçadas anteriormente. Assim, para este indicador foi estabelecida a variável divulgação dos pontos que necessitam de melhorias, que avalia a evidenciação da análise, a partir da confrontação dos resultados alcançados com as metas estabelecidas, dos pontos da gestão que necessitam de melhorias.

Nos relatórios de 2003 a 2005 observou-se a inexistência de menção a qualquer análise dos pontos da gestão que necessitam de melhorias. Assim, a evidenciação do conteúdo para o período de 2003 a 2005, tende a ser RESTRITA. No relatório referente ao $4^{\circ}$ trimestre/2006, todavia, observou-se que o gestor evidencia alguns problemas enfrentados pela gestão. Essa tendência é constatada no item 12 do relatório referente a 2006 "Atividades da Subsecretaria de Vigilância à Saúde (...)", como a persistência de dificuldades gerenciais em decorrência da estrutura orgânica 
da Divisão e ainda o impacto dessas dificuldades nos resultados alcançados pela gestão. Dessa forma, a evidenciação do conteúdo avaliado nesta variável, para 2006, tende a ser MÉDIA.

Glautier e Underdown (1994) afirmam que para a informação seja neutra é necessário que a mesma não seja escolhida ou selecionada pelo gestor e, ainda segundo eles, a confiabilidade das informações pressupõe neutralidade.

Hendriksen e Van Breda (1999), por sua vez, consideram que a informação para ser confiável deve ser isenta de vieses. Contudo, a decisão de divulgar ou não determinada informação que não esteja contida dentre aqueles itens determinados pela legislação é tomada pelo gestor, uma vez que é ele quem presta contas.

Nesse sentido, para que se possa garantir razoável segurança de neutralidade das informações apresentadas aos conselheiros, faz-se necessário a divulgação não apenas dos resultados positivos alcançados pela gestão, mas também das dificuldades encontradas na gestão dos recursos e das metas não alcançados.

O próximo indicador tratado reporta-se à precisão da informação, que segundo Glautier e Underdown (1994), está ligada a não omissão de informações, pois isso poderia causar uma falsa percepção ou direcionar para um entendimento não confiável ou deficiente. Neste indicador foi estabelecida a variável evidenciação do conteúdo legal, cujo objetivo é avaliar se o conteúdo exigido pelas normas que regem a prestação de contas está sendo evidenciado.

De acordo com a Lei $n^{\circ}$. 8689/1993 e com a Resolução do Conselho Nacional de Saúde $n^{\circ}$. 333/2003 há a determinação de que os relatórios de prestação de contas contenham o andamento da agenda de saúde pactuada; relatório de gestão; montante, fonte e forma de aplicação dos recursos aplicados; auditorias iniciadas e concluídas no período; e oferta e produção de serviços na rede assistencial.

Nos relatórios de 2003 a 2006 observou-se a divulgação dos itens: montante, fonte e forma de aplicação dos recursos; auditorias iniciadas e concluídas no período; e oferta e produção de serviços na rede assistencial.

Contudo, os itens andamento da agenda de saúde pactuada e relatório de gestão não foram encontrados explicitamente nos relatórios. No que diz respeito a estes dois últimos itens, a legislação não define o que deve ser divulgado quando se refere cada um deles. 0 gestor, por sua vez, não os evidencia de forma separada como o faz com os outros itens e, também, não diz o que entende por cada um deles. Assim, considerando que foram encontrados itens exigidos pelas normas que regem a prestação de contas e itens que não foram evidenciados, tem-se que a evidenciação do conteúdo avaliado por esta variável, no período de 2003 a 2006, tende a ser MÉDIA.

Para Glautier e Underdown (1994) a confiabilidade das informações apresentadas ao usuário pressupõe a ausência de omissão de informações. A evidenciação incompleta do conteúdo exigido pela legislação, como aponta os resultados da variável evidenciação do conteúdo legal, reduz a importância dos relatórios de prestação de contas como ferramenta de auxílio aos conselheiros no exercício de suas atribuições 
legais, haja vista que sua ausência dificulta o controle da execução das políticas de saúde e a formulação de estratégias (O’DONNELL, 1998; DAHL,1997).

O último indicador - prudência - está relacionado à preocupação em estabelecer estimativas quanto à ocorrência de eventos futuros que no momento de sua elaboração são incertos de ocorrerem (GLAUTIER; UNDERDOWN, 1994). Para este indicador foi estabelecida a variável reserva de recursos financeiros frente a eventos incertos e eventuais, que avalia a evidenciação de possíveis eventos futuros que possam vir a afetar negativamente a saúde pública e a respectiva estimativa da necessidade e reserva de recursos financeiros para enfrentar o problema.

Nos relatórios de 2003 a 2006 observou-se a ausência de qualquer evidência da estimativa e reserva de recursos necessários para fazer frente a eventos contingentes que possam vir a afetar negativamente a saúde da população. Assim, tem-se que a evidenciação do conteúdo proposto por esta variável, no período de 2003 a 2006, tende a ser RESTRITA.

A evidenciação dos planos a serem adotados pela gestão frente a eventos incertos e eventuais que possam vir a afetar negativamente a saúde da população é necessária para que o Conselho possa avaliar tais planos e, caso entenda necessário faça sugestões e/ou cobre do Executivo a adoção de medidas não previstas pelo gestor, que contribui para o aperfeiçoamento da gestão. Tal atitude pode, por outro lado, em momentos futuros, facilitar a justificativa dos resultados obtidos na realização dos planos contingenciais por parte do gestor, uma vez que ao Conselho foi dado, de antemão, conhecimento das medidas tomadas para atenuar os problemas enfrentados pela saúde pública.

\section{CONSIDERAÇÕES FINAIS}

Os resultados obtidos pela análise dos relatórios de prestação de contas da SES/DF ao CSDF demonstram que estes não possuem as características qualitativas necessárias para que o Conselho possa exercer suas atribuições constitucionais.

Na dimensão Materialidade a informação possui uma tendência "média", haja vista que esta não é divulgada de modo analítico. Como agravante, a SES/DF não retorna ao Conselho que decisão foi tomada a partir das recomendações alusivas dos pareceres, dificultando o exercício do controle social.

Na dimensão Relevância, a análise dos resultados apontou a mesma tendência - "média" - uma vez que não há a divulgação de metas por programa de saúde, bem como não há informação discricionária dos recursos orçamentários por programa de saúde, além de não ter períodos previamente definidos para a disponibilização dos relatórios de prestação de contas.

Quanto à análise das informações avaliadas pela dimensão Confiabilidade, os resultados sugeriram que a evidenciação de tais informações tende a ser "restrita". 
Essa tendência demonstra que a informação não é divulgada, configurando uma deficiência na elaboração e divulgação de informações que poderiam contribuir para assegurar a confiabilidade dos relatórios de prestação de contas. Tal característica é um fator que pode ser prejudicial à utilidade dos relatórios de prestação de contas, pois mesmo que o seu conteúdo seja material e relevante, se não apresentar razoável segurança quanto à sua confiabilidade provavelmente não será utilizado pelo usuário, neste caso o conselheiro, em suas decisões mais importantes.

Portanto, os resultados mostraram que as informações divulgadas não são aptas a possibilitar efetivamente o acompanhamento e a avaliação dos atos e resultados da gestão, e consequentemente, não colaboraram para o exercício das atribuições legais de formulação de estratégias e de controle da execução da política pública de saúde. Desta forma, o controle social, exercido aqui pelo CSDF, fica prejudicado, no sentido de fiscalizar as atividades exercidas pelo SES/DF. Além disso, as informações divulgadas não possibilitam a avaliação quanto à oportunidade da disponibilização dos relatórios de prestação de contas e quanto à predição de objetivos futuros relacionados às ações e serviços públicos de saúde.

Entende-se que o percurso feito entre SES/DF e Conselho, no sentido de melhorar a qualidade do conteúdo evidenciado pelos relatórios de prestação de contas, que o gestor evidencie no exercício financeiro o total acumulado de recursos aplicados nas ações e serviços de saúde e, também, o quantitativo realizado no trimestre referente à prestação de contas discriminando os recursos aplicados por ações e por programas de governo.

À medida que essas informações forem apresentadas nos relatórios de prestação de contas espera-se que o exercício da participação da comunidade por meio do Conselho se fortaleça, bem como favoreça o processo de tomada de decisão acerca da política pública local de saúde.

A principal contribuição deste estudo está na proposição de um instrumento que possibilita aos conselheiros de saúde avaliarem as informações contidas nos relatórios das secretarias de saúde, permitindo uma maior cobrança por esclarecimentos no processo de prestação de contas e, consequentemente, um melhor exercício do controle social. Cumpre salientar que o referido instrumento possui limitações na medida em que está restrito às variáveis que o compõe.

Como sugestões para futuras pesquisas, a questão da leitura da prestação de contas pode ser objeto de estudo(s) no sentido de identificar as dificuldades encontradas pelos conselheiros. Além disso, o estudo poderá ser aplicado nos Conselhos de Saúde dos demais Estados, Capitais e Municípios brasileiros.

\section{REFERÊNCIAS}

BICALHO, Milton dos Santos. Conselheiros de saúde construindo o controle social do SUS. Psicologia em Revista. Belo Horizonte, v. 10, 14, p. 149-154, dez-2003. 
BRASIL. Constituição da República Federativa do Brasil. Promulgada em 5 de outubro de 1988. Brasília. Disponível em : <http://www.presidencia.gov.br>. Acesso em: 06 de fevereiro de 2007.

BRASIL. Lei $n^{\circ}$. 8.689, de 27 de julho de 1993. Dispõe sobre a extinção do Instituto Nacional de Assistência Médica da Previdência Social (Inamps) e dá outras providências. Brasília-DF, 27 jul. 1993. Disponível em: <http://www.presidencia.gov.br>. Acesso em: 06 de fevereiro de 2007.

BRASIL. Conselho Nacional de Saúde. Resolução nº 333, de 04 de novembro de 2003. Aprova as diretrizes para criação, reformulação, estruturação e funcionamento dos conselhos de saúde. Brasília-DF. Disponível em: <http://www.saude.gov.br>. Acesso em: 06 de fevereiro de 2007.

CAMPOS, Anna Maria. Accountability: quando poderemos traduzi-la para o português? Revista de Administração Pública. Rio de Janeiro, fev./abr. 1990.

CARVALHO, Deusvaldo. Orçamento e Contabilidade Pública. 2 ed. Rio de Janeiro: Elsevier, 2006.

CLAD - CENTRO LATINOAMERICANO DE ADMINISTRACIÓN PARA EL DESARROLLO. La responsabilización en la nueva gestión pública latinoamericana. Buen

DAHL, Robert Alan. Poliarquia: participação e oposição. São Paulo: Universidade de São Paulo, 1997.

DISTRITO FEDERAL. Lei $\mathrm{n}^{\circ}$. 3.157 de 28 de maio de 2003. Dispõe sobre o Plano Plurianual do Distrito Federal para o período de 2004 a 2007. Brasília-DF. Disponível em: <http: / /www.distritofederal.df.gov.br> Acesso em 17 de maio de 2007.

DISTRITO FEDERAL. Lei $\mathrm{n}^{\circ} .469$ de 25 de junho de 1993. Altera as atribuições e a composição do Conselho de Saúde do Distrito Federal, modificando a Lei 70, de 22 de dezembro de 1989, com o propósito de implantar as recomendações da Resolução $n^{\circ}$ 33 de 22 de dezembro de 1992, do Conselho Nacional de Saúde. Brasília-DF. Disponível em: <http://sileg.sga.df.gov.br/sileg/ > Acesso em 17 de maio de 2007.

GIL, Antonio Carlos. Métodos e Técnicas de Pesquisa Social. 5. ed. São Paulo: Atlas, 1999.

GLAUTIER, M. W. E.; UNDERDOWN, B. Accounting theory and pratice. 5th ed. London: Pitman, 1994.

HENDRIKSEN, Eldon S.; VAN BREDA, Michael F. Teoria da Contabilidade. São Paulo: Atlas, 1999.

IUDíCIBUS, Sérgio de. MARTINS, Eliseu. GELBCKE, Ernesto Rubens. Manual de Contabilidade das Sociedades por Ações. 6. ed. São Paulo: Atlas, 2003.

JONAS, G. J.; BLANCHET, J. Assessing quality of financial reporting. Accounting Horizons, v. 14, 3, sep., 2000, p. 353-63. 
MOSHER, Frederich. Democracy and public service. New York, Oxford University, 1968.

O’DONNELL, Guillermo. Accountability horizontal e novas poliarquias. Lua nova, São Paulo, n. 44, p. 27-54, 1998.

OLIVEIRA, Arildo da Silva, Perspectivas para o controle social e a transparência da administração pública, in Prêmio Serzedello Corrêa 2001: Monografias Vencedoras: Perspectivas para o Controle social e a Transparência da Administração Pública. Brasília: TCU, 2002.

RIAHI-BELKAOUI, Ahmed. Accounting Theory. 5th ed. London: Thomson Learning, 2004.

SILVA, Andréa de Oliveira. Comunidades participativas e a deliberação da políticapública de saúde: um estudo comparativo de conselhos locais de saúde de PortoAlegre (Brasil) e Montevidéu (Uruguai). 2005. $157 \mathrm{f}$. Tese (Doutorado em Programa de Integração da América Latina) - Programa de Pós Graduação em integração da América Latina, Universidade de São Paulo, São Paulo, 2005. 


\section{ENDEREÇOS DOS AUTORES:}

\section{Andrea de Oliveira Gonçalves}

Universidade de Brasília, FUP

Área Universitária n. 1 - Vila Nossa Senhora de Fátima

Brasilia, DF - Brasil

73300-000

\section{Rodrigo Souza Gonçalves}

Universidade de Brasília

Fundação Universidade de Brasília, Cca Departamento de Ciências Contábeis e Atuariais

Campus Universitário Darcy Ribeiro - Asa Norte

Brasilia, DF - Brasil

70910900

\section{Paulo Roberto Barbosa Lustosa}

Universidade de Brasília

CCA - Departamento de Ciências Contábeis e Atuariais

Campus Universitário Darcy Ribeiro - Asa Norte

BRASILIA, DF - Brasil

70910-900

\section{Emanoel Carlos Celestino}

Universidade de Brasília

CCA - Departamento de Ciências Contábeis e Atuariais

Campus Universitário Darcy Ribeiro - Asa Norte

BRASILIA, DF - Brasil

70910-900 